\title{
Article \\ Discussion on Criterion of Determination of the Kinetic Parameters of the Linear Heating Reactions
}

\author{
Kui Li ${ }^{1} \mathbb{D}$, Wei Zhang ${ }^{1, * \mathbb{D}}$, Menglong Fu ${ }^{2}$, Chengzhi $\mathrm{Li}^{2}$ and Zhengliang Xue ${ }^{2}$ \\ 1 The State Key Laboratory of Refractories and Metallurgy, Wuhan University of Science and Technology, \\ Wuhan 430081, China; likui@wust.edu.cn \\ 2 Key Laboratory for Ferrous Metallurgy and Resources Utilization of Ministry of Education, Wuhan University \\ of Science and Technology, Wuhan 430081, China; fml@wust.edu.cn (M.F.); chengzhi.li@wust.edu.cn (C.L.); \\ xuezhengliang@wust.edu.cn (Z.X.) \\ * Correspondence: wei_zhang@wust.edu.cn
}

check for updates

Citation: Li, K.; Zhang, W.; Fu, M.;

Li, C.; Xue, Z. Discussion on

Criterion of Determination of the

Kinetic Parameters of the Linear

Heating Reactions. Minerals 2022, 12,

81. https://doi.org/10.3390/

$\min 12010081$

Academic Editors: Shuai Wang,

Xingjie Wang, Jia Yang and

M Akbar Rhamdhani

Received: 6 December 2021

Accepted: 6 January 2022

Published: 10 January 2022

Publisher's Note: MDPI stays neutral with regard to jurisdictional claims in published maps and institutional affiliations.

Copyright: () 2022 by the authors Licensee MDPI, Basel, Switzerland. This article is an open access article distributed under the terms and conditions of the Creative Commons Attribution (CC BY) license (https:// creativecommons.org/licenses/by/ $4.0 /)$.

\begin{abstract}
Generally, the linear correlation coefficient is one of the most significant criteria to appraise the kinetic parameters computed from different reaction models. Actually, the optimal kinetic triplet should meet the following two requirements: first, it can be used to reproduce the original kinetic process; second, it can be applied to predict the other kinetic process. The aim of this paper is to attempt to prove that the common criteria are insufficient for meeting the above two purposes simultaneously. In this paper, the explicit Euler method and Taylor expansion are presented to numerically predict the kinetic process of linear heating reactions. The mean square error is introduced to assess the prediction results. The kinetic processes of hematite reduced to iron at different heating rates $(8,10$ and $18 \mathrm{~K} / \mathrm{min})$ are utilized for validation and evaluation. The predicted results of the reduction of $\mathrm{Fe}_{2} \mathrm{O}_{3} \rightarrow \mathrm{Fe}_{3} \mathrm{O}_{4}$ indicated that the inferior linear correlation coefficient did provide better kinetic predicted curves. In conclusion, to satisfy the above two requirements of reproduction and prediction, the correlation coefficient is an insufficient criterion. In order to overcome this drawback, two kinds of numerical prediction methods are introduced, and the mean square error of the prediction is suggested as a superior criterion for evaluation.
\end{abstract}

Keywords: correlation coefficient; kinetic parameters; criterion; hematite; reduction

\section{Introduction}

Overall, to elucidate the reaction mechanisms and describe the kinetic process of the experimental data, the kinetic triplet (i.e., the activation energy, $E$; the pre-exponential factor, $A$; the reaction model, $f(\alpha)$ ) needs to be evaluated using kinetic analysis methods. In the practical application, the kinetic triplet is a momentous parameter for the resource recovery process of waste ore in mineral engineering and metallurgical engineering [1-6]. The kinetic analysis methods can be classified into the following two categories: one is isothermal kinetics and the other is nonisothermal kinetics. Prior to isothermal kinetic studies, thermogravimetric analyses are widely applied to characterize various materials, due to some advantages presented by many researchers $[7,8]$. The model-fitting method was widely used to investigate the reaction mechanism in quantities of literature from thermal-stimulated experimental data, based on a constant heating temperature program (TGA, DSC, DTA, etc.) [9-11]. Model-fitting approaches allow for the use of various reaction models $(f(\alpha))$ to fit experimental data, and then each reaction model produces a single pair of $E$ and $A$ [12]. Because of the physical interpretation of activation energy, its values derived from different models are usually proved to be in a rational range, with the same order of magnitudes. Identifying the optimal kinetic triplet from the above-produced kinetic parameters is thorny and strenuous work. Commonly, the kinetic parameters chosen by the linear correlation coefficient can accurately reproduce the original kinetic curves, whereas, for the practical application, the kinetic parameters should successfully 
predict the other kinetic curves with the same mechanism. Therefore, is it reasonable to select the kinetic parameters according to the correlation coefficient only? This question is seldom presented, but is a real problem for the application of nonisothermal analysis. Actually, the most persuasive criterion to choose kinetic parameters is satisfaction to the experimental and predicted data. However, the kinetic parameters obtained using the model-fitting method are rarely applied to predict the nonisothermal kinetic process.

The reduction reaction of hematite is one of the most widely investigated reactions in history [13-17]. In general, there are two kinds of reaction mechanisms for the hematite reduction reaction, which depends on the reaction temperature. The first mechanism is that hematite converts to magnetite and then directly to iron below $576{ }^{\circ} \mathrm{C}$. Nevertheless, the reaction mechanism will experience $\mathrm{Fe}_{2} \mathrm{O}_{3} \rightarrow \mathrm{Fe}_{3} \mathrm{O}_{4} \rightarrow \mathrm{Fe}_{x} \mathrm{O} \rightarrow \mathrm{Fe}$ above $576^{\circ} \mathrm{C}$ [18]. In this paper, we take the low-temperature (below $576{ }^{\circ} \mathrm{C}$ ) reduction of hematite as an example to clarify that the correlation coefficient is an insufficient criterion to assess the kinetic triplet.

\section{Theoretical Models}

\subsection{Nonisothermal Kinetics}

Before the instruments for nonisothermal measurements (TGA, DSC, DTA, etc.) were invented, the concepts of solid-state kinetics had already been established [19-21]. Nearly all kinetics analysis methods are based on the following equation [22,23]:

$$
\frac{\mathrm{d} \alpha}{\mathrm{d} t}=k(T) f(\alpha)
$$

where $\alpha$ denotes the extent of the conversion, $t$ [min] is the reaction time, $k(T)\left[\mathrm{min}^{-1}\right]$ is the reaction constant, expressed by the Arrhenius equation, and $f(\alpha)$ denotes the reaction model. Some of the most common reaction models are presented in Table 1 [22].

Table 1. Reaction models of solid-state kinetics.

\begin{tabular}{|c|c|c|c|c|}
\hline & Reaction Model & Code & $f(\alpha)$ & $g(\alpha)$ \\
\hline 1 & Power law & $\mathrm{p} 4$ & $4 \alpha^{3 / 4}$ & $\alpha^{1 / 4}$ \\
\hline 2 & Power law & P3 & $3 \alpha^{2 / 3}$ & $\alpha^{1 / 3}$ \\
\hline 3 & Power law & P2 & $2 \alpha^{1 / 2}$ & $\alpha^{1 / 2}$ \\
\hline 4 & Power law & $\mathrm{P} 2 / 3$ & $2 / 3 \alpha^{-1 / 2}$ & $\alpha^{3 / 2}$ \\
\hline 5 & $\begin{array}{l}\text { One-dimensional } \\
\text { diffusion }\end{array}$ & D1 & $1 / 2 \alpha^{-1}$ & $\alpha^{2}$ \\
\hline 6 & Mampel (first order) & F1 & $1-\alpha$ & $-\ln (1-\alpha)$ \\
\hline 7 & Awrami-Erofeev & A4 & $4(1-\alpha)[-\ln (1-\alpha)]^{3 / 4}$ & {$[-\ln (1-\alpha)]^{1 / 4}$} \\
\hline 8 & Avrami-Erofeev & A3 & $3(1-\alpha)[-\ln (1-\alpha)]^{2 / 3}$ & {$[-\ln (1-\alpha)]^{1 / 3}$} \\
\hline 9 & Avrami-Erofeev & A2 & $2(1-\alpha)[-\ln (1-\alpha)]^{1 / 2}$ & {$[-\ln (1-\alpha)]^{1 / 2}$} \\
\hline 10 & $\begin{array}{l}\text { Three-dimensional } \\
\text { diffusion }\end{array}$ & D3 & $3 / 2(1-\alpha)^{2 / 3}\left[1-(1-\alpha)^{1 / 3}\right]^{-1}$ & {$\left[1-(1-\alpha)^{1 / 3}\right]^{2}$} \\
\hline 11 & Contracting sphere & R3 & $3(1-\alpha)^{2 / 3}$ & $1-(1-\alpha)^{1 / 3}$ \\
\hline 12 & Contracting cylinder & $\mathrm{R} 2$ & $2(1-\alpha)^{1 / 2}$ & $1-(1-\alpha)^{1 / 2}$ \\
\hline 13 & $\begin{array}{l}\text { Two-dimensional } \\
\text { diffusion }\end{array}$ & D2 & {$[-\ln (1-\alpha)]^{-1}$} & $(1-\alpha) \ln (1-\alpha)+\alpha$ \\
\hline
\end{tabular}

The temperature dependence can be presented through the Arrhenius equation, as follows:

$$
k(T)=A \exp \left(\frac{-E}{R T}\right)
$$

where $A\left[\mathrm{~min}^{-1}\right]$ is the pre-exponential factor, $E[\mathrm{~J} / \mathrm{mol}]$ is the activation energy of the reaction, $R$ is the gas constant, and $T[\mathrm{~K}]$ is the reaction temperature. 
Combining Equations (1) and (2) yields Equation (3), as follows:

$$
\frac{\mathrm{d} \alpha}{\mathrm{d} t}=A \exp \left(\frac{-E}{R T}\right) f(\alpha)
$$

For nonisothermal conditions, a constant heating rate $\beta$ is usually adopted, thus the following equation is applied:

$$
\beta=\frac{\mathrm{d} T}{\mathrm{~d} t}
$$

where $\beta[\mathrm{K} / \mathrm{min}]$ is the linear heating rate. Combining Equations (3) and (4) means that the explicit temporal dependence in Equation (3) is eliminated through the following trivial transformation:

$$
\frac{\mathrm{d} \alpha}{\mathrm{d} T}=\frac{A}{\beta} \exp (-E / R T) f(\alpha)
$$

Taking the natural logarithm of Equation (3) leads to the following:

$$
\ln \left(\frac{\mathrm{d} \alpha / \mathrm{d} t}{f(\alpha)}\right)=\ln A-\frac{E}{R T}
$$

Using the Sharp-Wentworth method [24], a plot of $\ln \left(\frac{\mathrm{d} \alpha / \mathrm{d} t}{f(\alpha)}\right)$ against $\frac{1}{T}$ should result in a straight line, with the slope of $-E / R$ and the intercept of $\ln A$, then the activation energy and pre-exponential factor can be calculated. The reaction is regularly regarded as the first order or other apparent reaction orders gained from the Freeman-Carroll [8] method.

The integral of Equation (5) yields the following:

$$
g(\alpha)=\int_{0}^{\alpha} \frac{\mathrm{d} \alpha}{f(\alpha)}=\frac{A}{\beta} \int_{T_{0}}^{T} \exp (-E / R T) \mathrm{d} T
$$

where $g(\alpha)$ is the integral form of the $1 / f(\alpha)$ (shown in Table 1 ), and $T_{0}$ is the initial reaction temperature. The right-hand expression of Equation (5) has no analytical solution, and many researchers $[7,25,26]$ have approached the analytical solutions with some mathematical simplifications. One of the most popular mathematical simplifications is the Coats-Redfern equation [7], which is as follows:

$$
\ln \frac{g(\alpha)}{T^{2}}=\ln \left(\frac{A R}{\beta E}\left[1-\frac{2 R T_{m}}{E}\right]\right)-\frac{E}{R T}
$$

where $T_{m}$ is the mean experimental temperature, and the Arrhenius parameters ( $E$ and $A$ ) can be derived from the plot of $\ln \frac{g(\alpha)}{T^{2}}$ against $\frac{1}{R T}$.

\subsection{The Criterion of Determination}

Regular kinetic analysis has the following two major purposes: one is theoretical and the other is practical. Theoretically, each member of the kinetic triplet $(A, E$, and $f(\alpha)$ ) represents a different physical concept [27]. $A$ is associated with the frequency of the vibrations of the activated complex and $E$ represents the energy barrier [28]. $f(\alpha)$ or $g(\alpha)$ is regarded as the reaction mechanism [29]. Practically, the kinetic triplet needed to provide a mathematical description of the kinetic process. Based on the mathematical description, not only the original kinetics data can be reproduced, but the other kinetic processes could also be numerically predicted [27]. When adopting the Sharp-Wentworth or Coats-Redfern methods to deal with experimental data, a set of kinetic triplets can be derived in different reaction models. Because of the existence of the "compensation effect", there is a strong linear correlation between the values $E$ and $\ln A$ computed from the corresponding reaction model $f(\alpha)$ [30]; most of the kinetic triplets can satisfactorily reproduce the original experimental data [12]. However, not all kinetic triplets can make a 
satisfying prediction. Therefore, how to choose optimal kinetic parameters is a significant problem.

For a same reaction, various fitting models will produce different coefficients of linear correlation, $r$. In many papers [31-33], the linear correlation, $r$, is usually estimated as a criterion for selection. A single pair of $A$ and $E$ is then commonly chosen, corresponding to a reaction model that gives the maximum absolute value of the correlation coefficient, $\left|r_{\max }\right|$ [12]. Actually, the maximum value of $|r|$ does not necessarily represent the most probable model in statistics [12,34-36]. Vyazovkin suggested combining the linear correlation, $r$, and the result of the isothermal kinetics prediction, based on nonisothermal kinetics parameters, to pick the kinetic triplet [12]. The prediction formula is as follows:

$$
t_{\alpha}=\frac{g(\alpha)}{A \exp \left(-E / R T_{0}\right)}
$$

where $T_{0}$ is the constant temperature (isothermal condition) and $t_{\alpha}$ is the time to reach the extent of conversion at the temperature $T_{0}$. Nevertheless, sometimes the method will be invalid. Whether the nonisothermal kinetic triplet can be applied to the isothermal condition is controversial [12,37]. Hence, a new idea that uses nonisothermal kinetics parameters to predict the nonisothermal kinetics process may be more reliable. Two numerical methods are introduced to evaluate the criterion, explained below.

\subsection{Explicit Euler Method}

When the activation energy, reaction order, and the pre-exponential factor are determined, the results of the numerical prediction can be obtained by using the explicit Euler method.

Combining Equations (3) and (4), we can obtain the following equation:

$$
\frac{\mathrm{d} \alpha}{\mathrm{d} t}=f_{k}=A \exp \left(\frac{-E}{R\left(T_{0}+t_{k} \beta\right)}\right) f(\alpha)
$$

Based on the explicit Euler formula, the numerical prediction formula can be obtained as follows:

$$
\left\{\begin{array}{l}
\alpha_{k+1}=\alpha_{k}+h f_{k} \\
\alpha_{0}=\alpha\left(t_{0}\right) \\
h=b / m
\end{array} \quad(k=0,1,2 \cdots, m-1)\right.
$$

where $k$ denotes the node of the Euler formula, $f_{k}\left[\mathrm{~min}^{-1}\right]$ denotes the slope of function $\alpha(t)$ at time $t_{k}$, $[\mathrm{min}], h$ [min] is the step length of the Euler formula, $m$ is the number of nodes, and $b$ [min] denotes the total reaction time. Regularly, $\alpha_{0}$ equals zero.

\subsection{Taylor Expansion Method}

Supposing the activation energy, reaction order, and the pre-exponential factor are given, the numerical solution of Equation (7) can be calculated using the Taylor expansion method, which is as follows:

$$
g(T)=\frac{A}{\beta} \int_{T_{0}}^{T} \exp (-E / R T) \mathrm{d} T
$$

where $g(T)$ is the original function of the above temperature integral. Equation (13) is deduced by second-order Taylor expansion of the original function, $g(T)$, as follows:

$$
g\left(T_{0}+\Delta T\right) \approx g\left(T_{0}\right)+g^{\prime}\left(T_{0}\right) \Delta T+\frac{1}{2 !} g^{\prime \prime}\left(T_{0}\right) \Delta T^{2}
$$


where the following applies:

$$
\begin{aligned}
g^{\prime}(T) & =\frac{A}{\beta} \exp (-E / R T) \\
g^{\prime \prime}(T) & =\frac{A E \exp (-E / R T)}{\beta R T^{2}}
\end{aligned}
$$

\subsection{Mean Square Error}

In order to appraise the deviation between the experimental value and the predicted value, the mean square error is defined as Equation (16), which is as follows:

$$
M S E=\frac{1}{N} \sum_{t=1}^{N}\left(y_{\text {exp }}-y_{\text {pre }}\right)^{2}
$$

where MSE denotes the mean square error, $N$ denotes the number of nodes, $y_{\exp }$ is the conversion rate of the experiment, and $y_{\text {pre }}$ is the predicted conversion rate by the explicit Euler or Taylor expansion methods.

It is worth emphasizing that the predicted data are simulated from the kinetic parameters derived from the other experimental data. For the same reaction, the smaller the mean square error is, the more accurate the prediction is.

\section{Experimental Procedure}

In order to validate the numerical prediction model, nonisothermal experiments are conducted and a differential thermal analyzer of STA 409 from NETZSCH (manufactured by NETZSCH-Gerätebau GmbH, Germany) is used as apparatus. The arrangement of the gas tube, $\mathrm{Al}_{2} \mathrm{O}_{3}$ crucible (sample carrier), gas monitor, thermal analyzer, and other auxiliary equipment is shown in Figure 1.

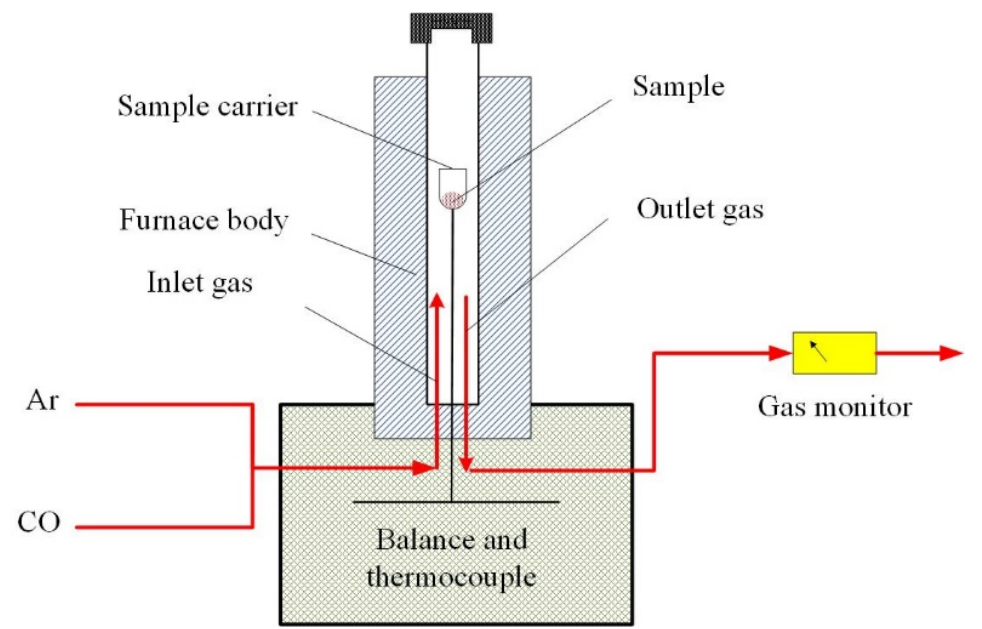

Figure 1. Experimental apparatus.

Chemical pure hematite powder with a purity of $99.0 \mathrm{wt} . \%$ (from Sinopharm Chemical Reagent Co., Ltd., Shanghai, China) was used as raw material. The powder was placed in the $\mathrm{Al}_{2} \mathrm{O}_{3}$ crucible, then it was appropriately placed on the weight sensor of the analyzer, and all the gas tubes were well sealed. Before being linearly heated, furnace atmosphere was cleansed from air with high-pure Ar gas, which was then substituted with pure $\mathrm{CO}$ at a flowrate of $30 \mathrm{~mL} / \mathrm{min}$. Consequently, the raw materials with masses of 370, 823, 610 and $335 \mathrm{mg}$ were heated at heating rates of $3,8,10$ and $18 \mathrm{~K} / \mathrm{min}$, respectively. When the reaction temperature was heated to $576{ }^{\circ} \mathrm{C}$, the material was cooled to room temperature in an inert Ar atmosphere. 


\section{Results and Discussion}

\subsection{Fitting Results}

Based on the principle of thermodynamics, when the reaction temperature is below $576{ }^{\circ} \mathrm{C}$ [38], the reduction of hematite can be divided into two steps. Firstly, hematite is reduced to magnetite, then magnetite is reduced to iron.

$$
\begin{gathered}
3 \mathrm{Fe}_{2} \mathrm{O}_{3}(\mathrm{~s})+\mathrm{CO}(\mathrm{g})=2 \mathrm{Fe}_{3} \mathrm{O}_{4}(\mathrm{~s})+\mathrm{CO}_{2}(\mathrm{~g}) \Delta \mathrm{G}^{\theta}=-42.227-0.048 T(\mathrm{~K}) \\
\frac{1}{4} \mathrm{Fe}_{3} \mathrm{O}_{4}(\mathrm{~s})+\mathrm{CO}(\mathrm{g})=\frac{3}{4} \mathrm{Fe}(\mathrm{s})+\mathrm{CO}_{2}(\mathrm{~g}) \Delta \mathrm{G}^{\theta}=-7.960+0.010 T(\mathrm{~K})
\end{gathered}
$$

The Gibbs energies of the reduction reactions of hematite to magnetite and magnetite to iron are negative under experimental conditions. Therefore, the above two reactions can occur in the experimental temperature range. The predominance area diagram of iron oxide reduction reactions is shown in Figure 2 [38].

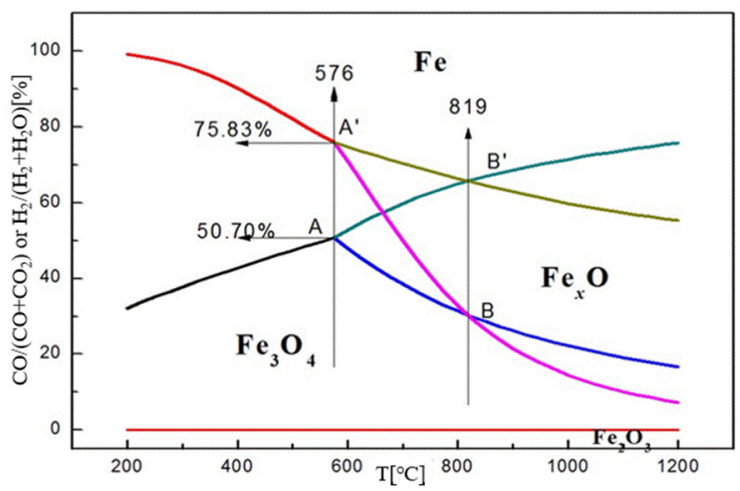

Figure 2. The predominance area diagram of iron oxide reduction reactions.

As shown in Figure 2, the reduction products of hematite are determined by reaction temperature and partial pressure of reduction gas. Point $\mathrm{A}$ and point $\mathrm{A}^{\prime}$ in Figure 2 are three-line intersections of the reactions reduced by $\mathrm{CO}$ and $\mathrm{H}_{2}$, respectively. Figure 2 can be divided into three parts by point $\mathrm{A}$. On the upper left part of point $\mathrm{A}$, the expected reduction product is $\mathrm{Fe}$; on the right part of point $\mathrm{A}, \mathrm{Fe}_{\mathrm{x}} \mathrm{O}$ is thermodynamically stable. Below the point $\mathrm{A}, \mathrm{Fe}_{3} \mathrm{O}_{4}$ is thermodynamically predominant. As a result, the low-temperature reduction of hematite includes two processes, i.e., $\mathrm{Fe}_{2} \mathrm{O}_{3} \rightarrow \mathrm{Fe}_{3} \mathrm{O}_{4}$ and $\mathrm{Fe}_{3} \mathrm{O}_{4} \rightarrow \mathrm{Fe}$.

The TG curves and DTG curves of the experimental data are shown in Figure 3.

According to the appearance of the DTG curve for the $3 \mathrm{~K} / \mathrm{min}$ heating rate, we can observe that there are two troughs $\left(329.1{ }^{\circ} \mathrm{C}\right.$ and $\left.438.0{ }^{\circ} \mathrm{C}\right)$, a peak $\left(349.0^{\circ} \mathrm{C}\right)$, and a significant inflection point $\left(530.0^{\circ} \mathrm{C}\right)$. The above phenomenon indicates that there are three reactions occurring. The first reaction began at $253.0^{\circ} \mathrm{C}$, and then the reaction rate reached the maximum at $329.1{ }^{\circ} \mathrm{C}$. From $329.1{ }^{\circ} \mathrm{C}$ to $438.0^{\circ} \mathrm{C}$, the reaction rate gradually decreases until it reaches zero. The mass loss of the first reaction is $4.78 \%$, which is larger than the theoretical mass loss of $\mathrm{Fe}_{2} \mathrm{O}_{3}$ reduced to $\mathrm{Fe}_{3} \mathrm{O}_{4}(3.33 \%)$. Practically, because of the non-stoichiometry of magnetite, the actual mass loss of $\mathrm{Fe}_{2} \mathrm{O}_{3} \rightarrow \mathrm{Fe}_{3} \mathrm{O}_{4}$ is $4.7 \%$ [18]. Therefore, the first reaction is hematite reduced to magnetite. The change from $329.1{ }^{\circ} \mathrm{C}$ to $438.0{ }^{\circ} \mathrm{C}$ denotes that the reaction of $\mathrm{Fe}_{3} \mathrm{O}_{4}$ reduced to $\mathrm{Fe}$ is proceeding. When the reaction temperature reaches about $530{ }^{\circ} \mathrm{C}$, the shape of the DTG curve changes, which alludes to a new reaction. The new reaction may be the carbon deposition reaction $\left(2 \mathrm{CO} \rightarrow \mathrm{C}+\mathrm{CO}_{2}\right)$ or the carburization reaction $\left(\mathrm{Fe}_{3} \mathrm{O}_{4}+6 \mathrm{C} \rightarrow \mathrm{Fe}_{3} \mathrm{C}+5 \mathrm{CO}\right)$. Therefore, we chose the temperature range of $329.1{ }^{\circ} \mathrm{C}$ to $520.0{ }^{\circ} \mathrm{C}$ to investigate the reaction of $\mathrm{Fe}_{3} \mathrm{O}_{4}$ reduced to Fe. The shapes of the DTG curves for $8,10,18 \mathrm{~K} / \mathrm{min}$ are similar to the shape of the DTG curve for $3 \mathrm{~K} / \mathrm{min}$, which indicates there are two reactions occurring $\left(\mathrm{Fe}_{2} \mathrm{O}_{3} \rightarrow \mathrm{Fe}_{3} \mathrm{O}_{4}\right.$ and then $\left.\mathrm{Fe}_{3} \mathrm{O}_{4} \rightarrow \mathrm{Fe}\right)$ during heating at $8,10,18 \mathrm{~K} / \mathrm{min}$. The selected temperature ranges of the above two reactions in each heating rate are shown in Table 2. 

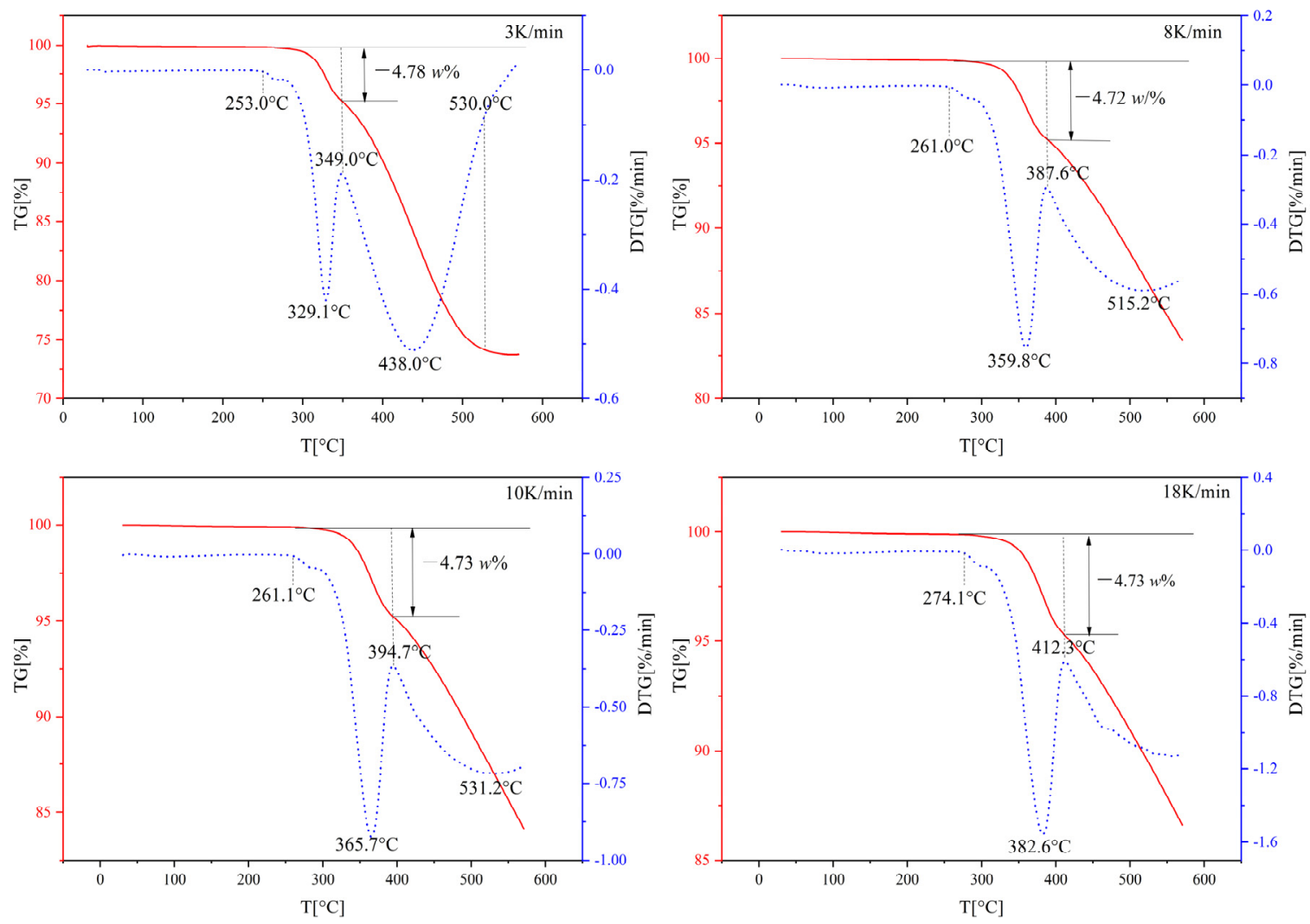

Figure 3. TG curves and DTG curves of experimental data. Red: TG curve. Blue: DTG curve.

Table 2. The selected temperature ranges of the two reactions.

\begin{tabular}{ccc}
\hline Heating Rate/(K/min) & $\mathrm{Fe}_{2} \mathrm{O}_{3} \rightarrow \mathrm{Fe}_{3} \mathrm{O}_{4}\left({ }^{\circ} \mathrm{C}\right)$ & $\mathrm{Fe}_{3} \mathrm{O}_{4} \rightarrow \mathrm{Fe}\left({ }^{\circ} \mathrm{C}\right)$ \\
\hline 3 & $253.0-329.1$ & $329.1-520.0$ \\
8 & $261.0-387.6$ & $387.6-520.0$ \\
10 & $261.1-394.7$ & $394.7-520.0$ \\
18 & $274.1-412.3$ & $412.3-520.0$ \\
\hline
\end{tabular}

The kinetic parameters of the hematite reduction reaction and the corresponding correlation coefficients at 3, 8, 10 and $18 \mathrm{~K} / \mathrm{min}$ heating rates are displayed in Tables 3 and 4 .

Table 3. The kinetic parameters of the reaction of $\mathrm{Fe}_{2} \mathrm{O}_{3} \rightarrow \mathrm{Fe}_{3} \mathrm{O}_{4}$ based on the optimal correlation coefficient.

\begin{tabular}{|c|c|c|c|c|c|c|c|c|}
\hline \multirow[b]{2}{*}{$\beta /(\mathrm{K} / \mathrm{min})$} & \multicolumn{5}{|c|}{ Sharp-Wentworth } & \multicolumn{3}{|c|}{ Coats-Redfern } \\
\hline & $\begin{array}{c}E \\
(\mathrm{~J} / \mathrm{mol})\end{array}$ & $\begin{array}{l}\text { Reaction } \\
\text { Order }\end{array}$ & $\ln _{(A / \mathrm{min})}$ & $r^{2}$ & $\begin{array}{c}E \\
(\mathrm{~J} / \mathrm{mol})\end{array}$ & $\begin{array}{c}\text { Reaction } \\
\text { Order }\end{array}$ & $\ln _{(A / \mathrm{min})}$ & $r^{2}$ \\
\hline 3 & 246,385 & First & 47.68 & 0.9992 & 176,498 & First & 33.28 & 0.9857 \\
\hline 8 & 179,333 & First & 35.25 & 0.9994 & 144,763 & First & 26.37 & 0.9875 \\
\hline 10 & 179,316 & First & 35.35 & 0.9989 & 147,216 & First & 26.78 & 0.9906 \\
\hline 18 & 171,360 & First & 34.15 & 0.9981 & 132,533 & First & 23.81 & 0.9796 \\
\hline
\end{tabular}


Table 4. The kinetic parameters of the reaction of $\mathrm{Fe}_{3} \mathrm{O}_{4} \rightarrow$ Fe based on the optimal correlation coefficient.

\begin{tabular}{|c|c|c|c|c|c|c|c|c|}
\hline \multirow[b]{2}{*}{$\beta /(\mathrm{K} / \mathrm{min})$} & \multicolumn{4}{|c|}{ Sharp-Wentworth } & \multicolumn{4}{|c|}{ Coats-Redfern } \\
\hline & $\begin{array}{c}E \\
(\mathrm{~J} / \mathrm{mol})\end{array}$ & $\begin{array}{l}\text { Reaction } \\
\text { Order }\end{array}$ & $\ln _{(A / \min )}$ & $r^{2}$ & $\begin{array}{c}E \\
(\mathrm{~J} / \mathrm{mol})\end{array}$ & $\begin{array}{l}\text { Reaction } \\
\text { Order }\end{array}$ & $\ln _{(A / \mathrm{min})}$ & $r^{2}$ \\
\hline 3 & 72,576 & First & 9.28 & 0.9994 & 81,382 & First & 10.57 & 0.9984 \\
\hline 8 & 56,040 & First & 6.48 & 0.9969 & 142,386 & Third & 21.39 & 0.9908 \\
\hline 10 & 58,440 & First & 7.32 & 0.9919 & 147,765 & Third & 22.38 & 0.9917 \\
\hline 18 & 63,649 & First & 8.44 & 0.9941 & 171,202 & Third & 26.53 & 0.9933 \\
\hline
\end{tabular}

\subsection{Results from Explicit Euler Method}

When the activation energy, reaction mechanism, and pre-exponential factor of a group of thermogravimetric data have been obtained in advance, the dependence of $\alpha$ on $t$ can be calculated using Equations (10) and (11) for an arbitrary heating rate experiment.

Figure 4 shows comparisons between the experimental data and the predicted results, using different kinetics parameters of $\mathrm{Fe}_{2} \mathrm{O}_{3}$ reduced to $\mathrm{Fe}_{3} \mathrm{O}_{4}$ by the explicit Euler method. In the sub-image of Figure 4, the reaction mechanisms are both first orders, and the kinetics parameters are achieved from the experimental data with the heating rate of $3 \mathrm{~K} / \mathrm{min}$; the pre-exponential factor and activation energy for the Sharp-Wentworth models are $5.12 \times 10^{20} \mathrm{~min}^{-1}$ and $246.39 \mathrm{~kJ} / \mathrm{mol}$, and for the Coats-Redfern models they are $2.85 \times 10^{14} \mathrm{~min}^{-1}$ and $176.50 \mathrm{~kJ} / \mathrm{mol}$, respectively.

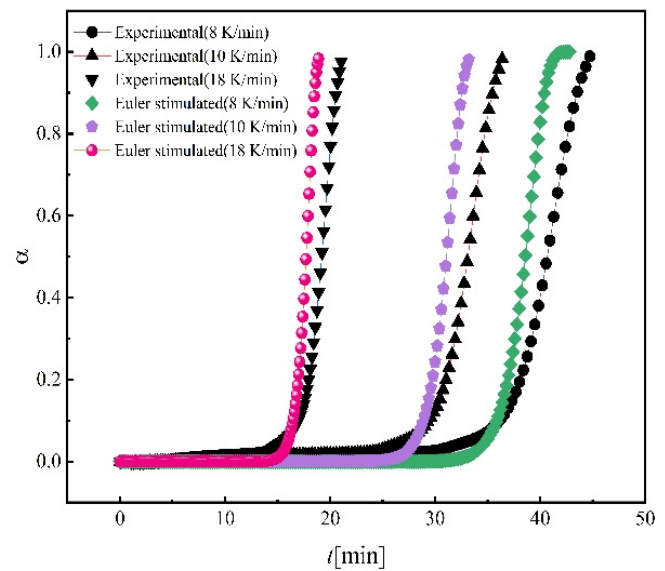

Sharp-Wentworth parameters

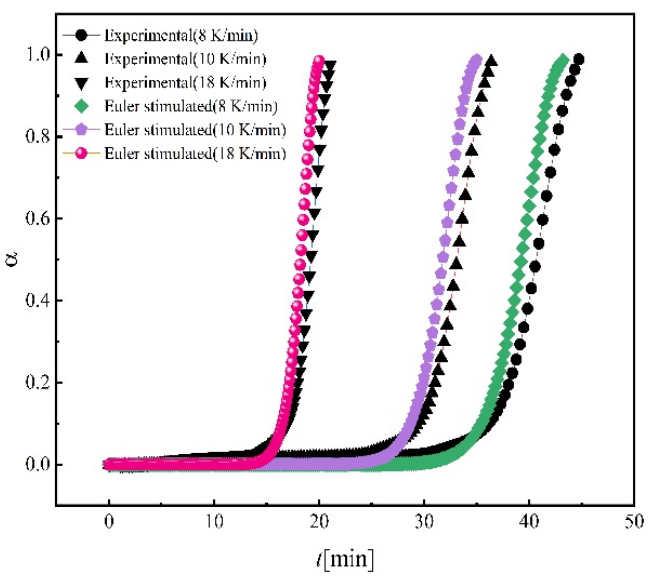

Coats-Redfern parameters

Figure 4. Experimental and predicted data using Sharp-Wentworth and Coats-Redfern parameters of $\mathrm{Fe}_{2} \mathrm{O}_{3} \rightarrow \mathrm{Fe}_{3} \mathrm{O}_{4}$ by explicit Euler method.

Figure 5 shows comparisons between the experimental data and the predicted results for the reaction of magnetite reduced to iron. The predicted results are based on kinetic parameters of the heating rate of $3 \mathrm{~K} / \mathrm{min}$. The reaction mechanisms of magnetite reduced to iron for the Sharp-Wentworth and Coats-Redfern methods are both first orders. The kinetic parameters used for the prediction are as follows: Sharp-Wentworth's preexponential factor and activation energy are $10,708 \mathrm{~min}^{-1}$ and $72.58 \mathrm{~kJ} / \mathrm{mol}$, respectively, and the pre-exponential factor and activation energy of Coats-Redfern are 38,901 $\mathrm{min}^{-1}$ and $81.38 \mathrm{~kJ} / \mathrm{mol}$, respectively.

For the reaction of hematite reduced to magnetite, according to Figure 4 , the results of the Coats-Redfern prediction are closer to the experimental values. The mean square errors of the Sharp-Wentworth and Coats-Redfern methods are calculated by Equation (18). Based on the formula of the mean square error, the number of nodes with heating rates of 8,10 and $18 \mathrm{~K} / \mathrm{min}$ are 70,65 and 53, respectively. 


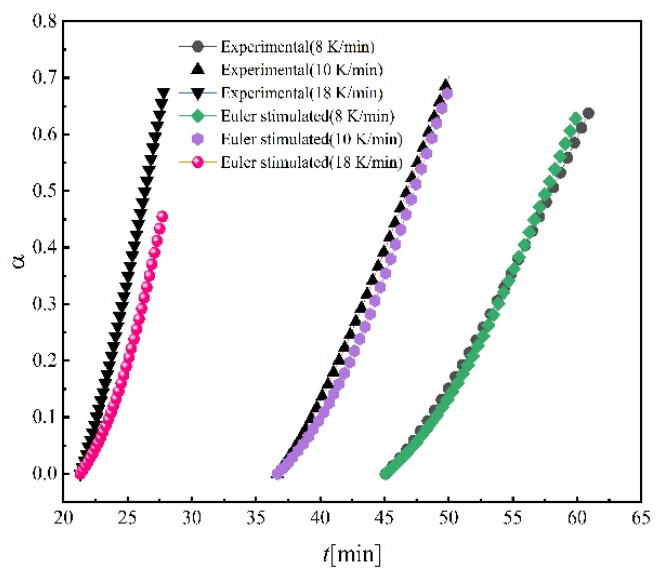

Sharp-Wentworth parameters

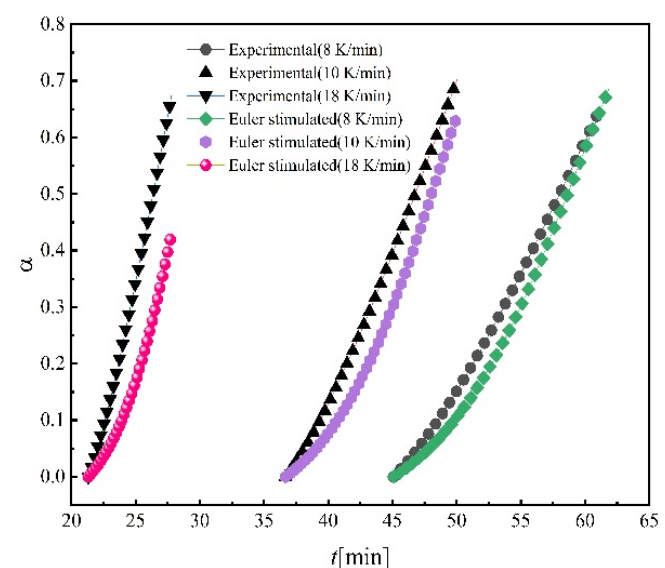

Coats-Redfern parameters

Figure 5. Experimental and predicted data using Sharp-Wentworth and Coats-Redfern parameters of $\mathrm{Fe}_{3} \mathrm{O}_{4} \rightarrow$ Fe by explicit Euler method.

According to the results of the mean square error in Table 5, for the same heating rate, the mean square value of the Coats-Redfern method is lower than that of the SharpWentworth method. Therefore, when the heating rate is $3 \mathrm{~K} / \mathrm{min}$, the kinetic parameters of hematite reduced to magnetite obtained by Coats-Redfern are superior to those obtained by the Sharp-Wentworth method.

Table 5. The mean square errors of the reaction of $\mathrm{Fe}_{2} \mathrm{O}_{3} \rightarrow \mathrm{Fe}_{3} \mathrm{O}_{4}$ for the explicit Euler method.

\begin{tabular}{|c|c|c|c|c|c|c|}
\hline \multicolumn{4}{|c|}{ Sharp-Wentworth } & \multicolumn{3}{|c|}{ Coats-Redfern } \\
\hline$\beta$ & $8 \mathrm{~K} / \mathrm{min}$ & $10 \mathrm{~K} / \mathrm{min}$ & $18 \mathrm{~K} / \mathrm{min}$ & $8 \mathrm{~K} / \mathrm{min}$ & $10 \mathrm{~K} / \mathrm{min}$ & $18 \mathrm{~K} / \mathrm{min}$ \\
\hline$N$ & 70 & 65 & 53 & 70 & 65 & 53 \\
\hline MSE & 0.0463 & 0.0563 & 0.0720 & 0.0171 & 0.0174 & 0.0191 \\
\hline
\end{tabular}

As for the reaction of magnetite reduced to iron, according to the mean square error formula, the number of nodes with heating rates of 3,8 and $18 \mathrm{~K} / \mathrm{min}$ are 83,88 and 66 , respectively.

The mean square errors of the Sharp-Wentworth method are smaller than those of the Coats-Redfern method in Table 6. Consequently, the kinetic parameters of magnetite reduced to iron, with a $3 \mathrm{~K} / \mathrm{min}$ heating rate, calculated by the Sharp-Wentworth method, are more preferable than those by the Coats-Redfern method. Significantly, whether the data of the Sharp-Wentworth method or the Coats-Redfern method are used, the predicted results of $18 \mathrm{~K} / \mathrm{min}$ are much different from the experimental data. This may be a result of the high heating rate or the speedy reduction process, which leads to a significant influence of inner diffusion on the dominant chemical reduction process.

Table 6. The mean square errors of the reaction of $\mathrm{Fe}_{3} \mathrm{O}_{4} \rightarrow \mathrm{Fe}$ for the explicit Euler method.

\begin{tabular}{ccccccc}
\hline & \multicolumn{3}{c}{ Sharp-Wentworth } & \multicolumn{3}{c}{ Coats-Redfern } \\
\hline$\beta$ & $8 \mathrm{~K} / \mathrm{min}$ & $10 \mathrm{~K} / \mathrm{min}$ & $18 \mathrm{~K} / \mathrm{min}$ & $8 \mathrm{~K} / \mathrm{min}$ & $10 \mathrm{~K} / \mathrm{min}$ & $18 \mathrm{~K} / \mathrm{min}$ \\
$N$ & 83 & 88 & 66 & 83 & 88 & 66 \\
$M S E$ & 0.0003 & 0.0013 & 0.0185 & 0.0019 & 0.0054 & 0.0262 \\
\hline
\end{tabular}

\subsection{Results from Taylor Expansion Method}

For a group of experimental data, the activation energy, reaction order, and the pre-exponential factor are gained in advance, since the left-hand side of Equation (7) can be integrated and the right-hand can be solved by using the recursive method, as Equations (13)-(15) demonstrated. With the help of a computer program, the calculated 
values of the reacted ratio $\alpha$ against time $t$ can be found. Finally, the kinetic processes of those experiments with other heating rates could also be numerically predicted.

Figure 6 depicts the predicted results for the reaction of hematite reduced to magnetite by using different kinetic triplets. The Taylor expansion method adopts the same parameters as the explicit Euler method.

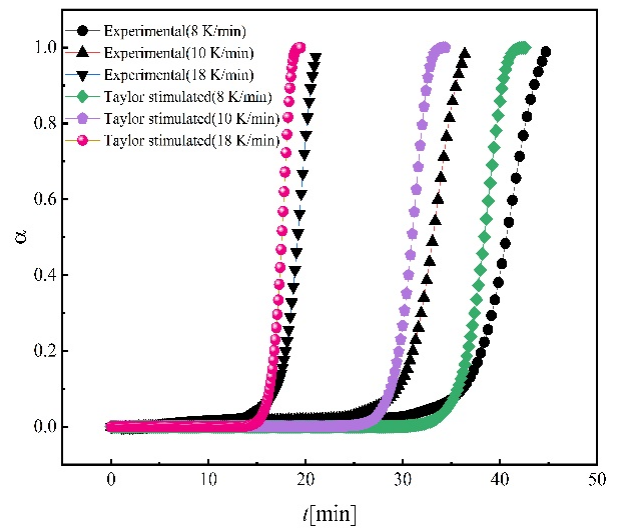

Sharp-Wentworth parameters

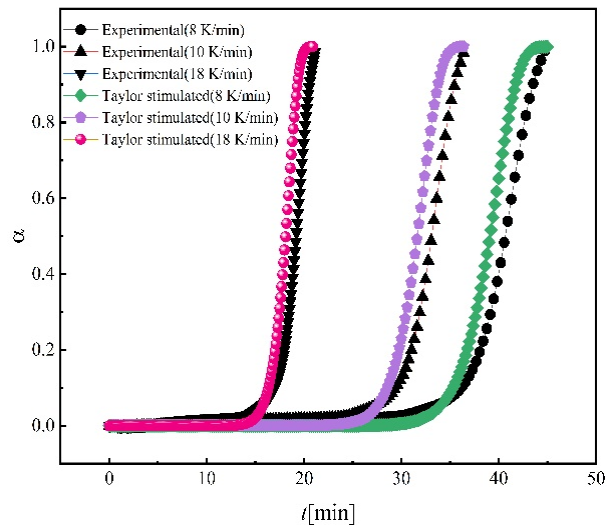

Coats-Redfern parameters

Figure 6. Experimental and predicted data using Sharp-Wentworth and Coats-Redfern parameters of $\mathrm{Fe}_{2} \mathrm{O}_{3} \rightarrow \mathrm{Fe}_{3} \mathrm{O}_{4}$ using the explicit Euler method.

According to Figure 6 and Table 7 , the same conclusion can be drawn, which is that the kinetic parameters of hematite reduced to magnetite, with a heating rate of $3 \mathrm{~K} / \mathrm{min}$, obtained by the Coats-Redfern method, are superior to those obtained by the SharpWentworth method.

Table 7. The mean square errors of the reaction of $\mathrm{Fe}_{2} \mathrm{O}_{3} \rightarrow \mathrm{Fe}_{3} \mathrm{O}_{4}$ for Taylor expansion.

\begin{tabular}{ccccccc}
\hline \multicolumn{3}{c}{ Sharp-Wentworth } & \multicolumn{3}{c}{ Coats-Redfern } \\
\hline$\beta$ & $8 \mathrm{~K} / \min$ & $10 \mathrm{~K} / \min$ & $18 \mathrm{~K} / \mathrm{min}$ & $8 \mathrm{~K} / \mathrm{min}$ & $10 \mathrm{~K} / \mathrm{min}$ & $18 \mathrm{~K} / \mathrm{min}$ \\
$N$ & 70 & 65 & 53 & 70 & 65 & 53 \\
$M S E$ & 0.0531 & 0.0618 & 0.0873 & 0.0200 & 0.0213 & 0.0264 \\
\hline
\end{tabular}

Figure 7 shows comparisons between the experimental and predicted data for the reaction of magnetite reduced to iron with the Taylor expansion method. In order to compare with the explicit Euler method, the same nodes are selected to calculate the mean square errors.

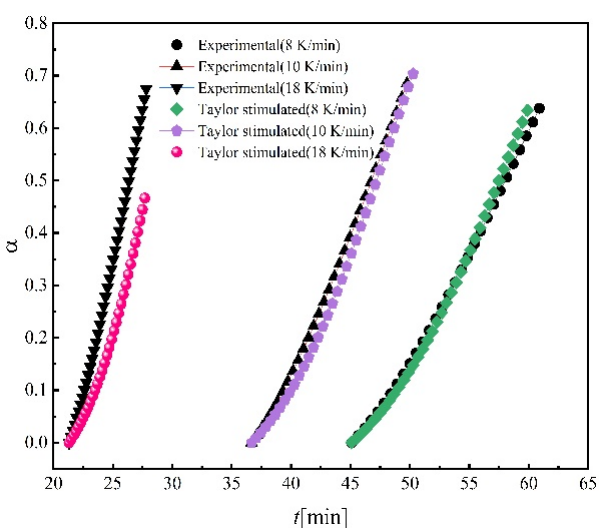

Sharp-Wentworth parameters

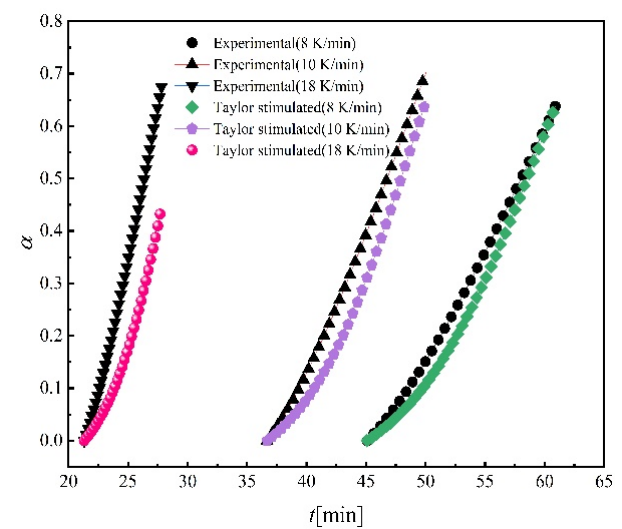

Coats-Redfern parameters

Figure 7. Experimental and predicted data using Sharp-Wentworth and Coats-Redfern parameters of $\mathrm{Fe}_{3} \mathrm{O}_{4} \rightarrow$ Fe by Taylor expansion. 
Based on the data of the mean square errors in Table 8 , the result predicted by using the Sharp-Wentworth method is better than that predicted by the Coats-Redfern method. Consequently, the kinetic parameters of magnetite to iron with a $3 \mathrm{~K} / \mathrm{min}$ heating rate, obtained by Sharp-Wentworth, are superior. When the heating rate is $18 \mathrm{~K} / \mathrm{min}$, the predicted results are still negative.

Table 8. The mean square errors of the reaction of $\mathrm{Fe}_{3} \mathrm{O}_{4} \rightarrow \mathrm{Fe}$ for Taylor expansion.

\begin{tabular}{ccccccc}
\hline & \multicolumn{1}{c}{ Sharp-Wentworth } & \multicolumn{3}{c}{ Coats-Redfern } \\
\hline$\beta$ & $8 \mathrm{~K} / \mathrm{min}$ & $10 \mathrm{~K} / \mathrm{min}$ & $18 \mathrm{~K} / \mathrm{min}$ & $8 \mathrm{~K} / \mathrm{min}$ & $10 \mathrm{~K} / \mathrm{min}$ & $18 \mathrm{~K} / \mathrm{min}$ \\
$N$ & 70 & 65 & 53 & 70 & 65 & 53 \\
$M S E$ & 0.0003 & 0.0010 & 0.0166 & 0.0016 & 0.0047 & 0.0238 \\
\hline
\end{tabular}

\section{Conclusions}

Model-fitting approaches are extensively used to obtain kinetics parameters in various fields. Normally, the correlation coefficient becomes the primary criterion to evaluate the kinetic parameters of different reaction models. One takes for granted that the kinetic parameters selected by the criterion are optimal. However, when the kinetic predicted results are taken into account, the actual situation may be unexpected. In this paper, the low-temperature reduction reaction of hematite was conducted in four different heating rate conditions $(3,8,10$ and $18 \mathrm{~K} / \mathrm{min})$. In order to evaluate the prediction ability of the kinetics parameters, the kinetics parameter of $3 \mathrm{~K} / \mathrm{min}$ heating rate is adopted to predict the kinetic curves of 8,10 and $18 \mathrm{~K} / \mathrm{min}$ heating rates. For the reduction step of $\mathrm{Fe}_{2} \mathrm{O}_{3} \rightarrow \mathrm{Fe}_{3} \mathrm{O}_{4}$, the prediction using the kinetics parameters of the Coats-Redfern $(r=0.9857)$ method should have been inferior to that of the Sharp-Wentworth $(r=0.9992)$ method, according to the correlation coefficient criterion. However, exactly the opposite is true for the sake of practical prediction. The kinetic parameters of Coats-Redfern $(r=0.9857)$ provide a better prediction result. In conclusion, although the correlation coefficient is widely used as the decisive criterion to assess kinetics parameters, it is shown to be insufficient when the capability of the practical prediction of kinetics parameters is taken into account.

Author Contributions: Conceptualization, W.Z.; methodology, M.F.; investigation, C.L.; resources, Z.X.; writing-original draft preparation, K.L.; writing-review and editing, W.Z. and K.L. All authors have read and agreed to the published version of the manuscript.

Funding: This research was funded by the National Natural Science Foundation of China (NSFC), grant numbers 51804228 and 52104340, and the China Scholarship Council (CSC), grant number 201908420169.

Acknowledgments: This work is financially supported by the National Natural Science Foundation of China (NSFC), grant numbers 51804228 and 52104340, and the China Scholarship Council (CSC), grant number 201908420169.

Conflicts of Interest: The authors declare no conflict of interest.

\section{Abbreviations}

$\begin{array}{lll}\alpha & \text { Conversion rate } & - \\ \beta & \text { Linear heating rate } & \mathrm{K} / \mathrm{min} \\ b & \text { Total reaction time } & \min \\ f & \text { Slope } & \min ^{-1} \\ m & \text { Number of nodes } & - \\ t & \text { Reaction time } & \min \\ h & \text { Step length } & \min \\ f(\alpha) & \text { Reaction model } & - \\ g(\alpha) & \text { The integral form of } \mathrm{f}(\alpha) & - \\ k(T) & \text { Reaction constant } & \min ^{-1} \\ A & \text { Pre-exponential factor } & \min ^{-1}\end{array}$




$\begin{array}{lll}E & \text { Activation energy } & \mathrm{J} / \mathrm{mol} \\ N & \text { Mean squared number of nodesnodes } & - \\ T & \text { Reaction temperature } & \mathrm{K} \\ \text { MSE } & \text { Mean square error } & - \\ \text { TGA } & \text { Thermal gravimetric analyzer } & - \\ \text { DSC } & \text { Differential scanning calorimetry } & - \\ \text { DTA } & \text { Differential thermal analysis } & -\end{array}$

\section{References}

1. Yuan, S.; Zhang, Q.; Yin, H.; Li, Y. Efficient iron recovery from iron tailings using advanced suspension reduction technology: A study of reaction kinetics, phase transformation, and structure evolution. J. Hazard. Mater. 2021, 404, 124067. [CrossRef]

2. Wan, X.; Shi, J.; Klemettinen, L.; Chen, M.; Taskinen, P.; Jokilaakso, A. Equilibrium phase relations of $\mathrm{CaO}_{-} \mathrm{SiO}_{2}-\mathrm{TiO} 2$ system at $1400{ }^{\circ} \mathrm{C}$ and oxygen partial pressure of 10-10 atm. J. Alloys Compd. 2020, 847, 156472. [CrossRef]

3. Zhang, J.; Zhang, W.; Xue, Z. Oxidation Kinetics of Vanadium Slag Roasting in the Presence of Calcium Oxide. Miner. Process. Extr. Metall. Rev. 2017, 38, 265-273. [CrossRef]

4. Liu, P.; Liu, C.; Hu, T.; Shi, J.; Zhang, L.; Liu, B.; Peng, J. Kinetic study of microwave enhanced mercury desorption for the regeneration of spent activated carbon supported mercuric chloride catalysts. Chem. Eng. J. 2021, 408, 127355. [CrossRef]

5. Peng, X.; Liu, W.; Liu, W.; Zhao, L.; Zhang, N.; Gu, X.; Zhou, S. Fluorite enhanced magnesium recovery from serpentine tailings: Kinetics and reaction mechanisms. Hydrometallurgy 2021, 201, 105571. [CrossRef]

6. Zhang, W.; Dai, J.; Li, C.; Yu, X.; Xue, Z.; Saxén, H. A Review on Explorations of the Oxygen Blast Furnace Process. Steel Res. Int. 2021, 92, 1-23. [CrossRef]

7. Coats, A.W.; Redfern, J.P. Kinetic parameters from thermogravimetric data. Nature 1964, 201, 68-69. [CrossRef]

8. Freeman, E.; Carroll, B. The application of thermoanalytical techniques to kinetics: The thermogravimetric evaluation of the kinetics of the decomposition of calcium oxalate monohydrate. J. Phys. Chem. 1975, 62, 394-397. [CrossRef]

9. Wang, T.X.; Ding, C.Y.; Lv, X.W.; Xuan, S.W.; Li, G. Reduction kinetics of MgO-doped calcium ferrites under CO-N 2 atmosphere J. Iron Steel Res. Int. 2019, 26, 1265-1272. [CrossRef]

10. Huang, Z.C.; Wu, K.; Hu, B.; Peng, H.; Jiang, T. Non-Isothermal Kinetics of Reduction Reaction of Oxidized Pellet Under Microwave Irradiation. J. Iron Steel Res. Int. 2012, 19, 1-4. [CrossRef]

11. Han, G.H.; Jiang, T.; Zhang, Y.B.; Huang, Y.F.; Li, G.H. High-temperature oxidation behavior of vanadium, titanium-bearing magnetite pellet. J. Iron Steel Res. Int. 2011, 18, 14-19. [CrossRef]

12. Vyazovkin, S.; Wight, C.A. Model-free and model-fitting approaches to kinetic analysis of isothermal and nonisothermal data. Thermochim. Acta 1999, 340-341, 53-68. [CrossRef]

13. Darken, L.S.; Gurry, R.W. The System Iron-Oxygen. I. The Wüstite Field and Related Equilibria. J. Am. Chem. Soc. 1945, 67, 1398-1412. [CrossRef]

14. Xing, L.Y.; Zou, Z.S.; Qu, Y.X.; Shao, L.; Zou, J.Q. Gas-Solid Reduction Behavior of In-flight Fine Hematite Ore Particles by Hydrogen. Steel Res. Int. 2019, 90, 1-10. [CrossRef]

15. Zheng, H.; Schenk, J.; Spreitzer, D.; Wolfinger, T.; Daghagheleh, O. Review on the Oxidation Behaviors and Kinetics of Magnetite in Particle Scale. Steel Res. Int. 2021, 92, 1-13. [CrossRef]

16. Pei, Z.; Peimin, G.; Dianwei, Z. study on reduction sequenece of hematite at low-temperature non-equilibrium state. Iorn Steel 2006, 41, 12-15.

17. Wimmers, O.J.; Arnoldy, P.; Moulijn, J.A. Determination of the reduction mechanism by temperature-programmed reduction: Application to small $\mathrm{Fe}_{2} \mathrm{O}_{3}$ particles. J. Phys. Chem. 1986, 90, 1331-1337. [CrossRef]

18. Zhang, W.; Zhang, J.H.; Zou, Z.S.; Li, Q.; Qi, Y.H. Influences of non-stoichiometry on thermodynamics and kinetics of iron oxides reduction processes. Ironmak. Steelmak. 2014, 41, 715-720. [CrossRef]

19. Hedvall, J.A. Reaktionsfähigkeit Fester Stoffe. Angew. Chem. 1938, 51, 150. [CrossRef]

20. Garner, W.E. Chemistry of the Solid State; Butterworths Scientific Publications: London, UK, 1955. [CrossRef]

21. Jost, W. Diffusion und Chemische Reaktionen in Festen Stoffen. Nature 1938, 142, 776. [CrossRef]

22. Vyazovkin, S.; Burnham, A.K.; Criado, J.M.; Pérez-Maqueda, L.A.; Popescu, C.; Sbirrazzuoli, N. ICTAC Kinetics Committee recommendations for performing kinetic computations on thermal analysis data. Thermochim. Acta 2011, 520,1-19. [CrossRef]

23. Han, Y.; Li, T.; Saito, K. Comprehensive method based on model free method and IKP method for evaluating kinetic parameters of solid state reactions. J. Comput. Chem. 2012, 33, 2516-2525. [CrossRef]

24. Sharp, J.H.; Wentworth, S.A. Kinetic analysis of thermogravimetric data. Anal. Chem. 1969, 41, 2060-2062. [CrossRef]

25. Ozawa, T. Kinetic analysis of derivative curves in thermal analysis. J. Therm. Anal. 1970, 2, 301-324. [CrossRef]

26. Sestak, J.; Satava, V.; Wendlandt, W.W. The study of heterogeneous processes by thermal analysis. Thermochim. Acta 1973, 7, 333-556. [CrossRef]

27. Vyazovkin, S. Model-free kinetics: Staying free of multiplying entities without necessity. J. Therm. Anal. Calorim. 2006, 83, 45-51. [CrossRef]

28. Glasstone, K.S.; Laidler, J.; Eyring, H. The Theory of Rate Processes. Nature 1941, 149, 509-510.

29. Galwey, A.K.; Brown, M. Thermal Decomposition of Ionic Solids; Elsevier Science: Amsterdam, The Netherlands, 1999. 
30. Brown, M.E.; Dollimore, D.; Galwey, A.K. Comprehensive Chemical Kinetics.Reactions in the Solid State; Elsevier: Amsterdam, The Netherlands, 1980; Volume 22.

31. Sardari, A.; Alamdari, E.K.; Noaparast, M.; Shafaei, S.Z. Kinetics of magnetite oxidation under non-isothermal conditions. Int. J. Miner. Metall. Mater. 2017, 24, 486-492. [CrossRef]

32. Barile, C.; Casavola, C.; Vimalathithan, P.K.; Pugliese, M.; Maiorano, V. Thermomechanical and morphological studies of CFRP tested in different environmental conditions. Materials 2018, 12, 63. [CrossRef]

33. Wang, F.; Qian, D.S.; Xiao, P.; Deng, S. Accelerating cementite precipitation during the non-isothermal process by applying tensile stress in GCr15 bearing steel. Materials 2018, 11, 2403. [CrossRef]

34. Johnson, N.L.; Leone, F.C. Statistics and Experimental Design in Engineering and the Physical Sciences; Wiley: New York, NY, USA, 1977.

35. Harnett, D.L. Statistical Methods; Addison-Wesley: Reading, UK, 1982.

36. Draper, N.R.; Smith, H. Applied Regression Analysis; Wiley: New York, NY, USA, 1981.

37. Vyazovkin, S.; Wight, C.A. Isothermal and nonisothermal reaction kinetics in solids: In search of ways toward consensus. J. Phys. Chem. A 1997, 101, 8279-8284. [CrossRef]

38. Zhang, W.; Zhang, J.; Li, Q.; He, Y.; Tang, B.; Li, M.; Zhang, Z.; Zou, Z. Thermodynamic analyses of iron oxides redox reactions. In Proceedings of the 8th Pacific Rim International Congress on Advanced Materials and Processing, PRICM 8, Waikoloa, HI, USA, 4-9 August 2013; Marquis, F., Ed.; Wiley: Waikoloa, HI, USA, 2013; pp. 777-789. 